\title{
The Problem of Translating the Prepositions at, in and on into Arabic: An Applied Linguistic Approach
}

\author{
Sadeq Ali Saad Al Yaari Corresponding author) \\ Independent Researcher, Dept. of English, College of Arts, King Saud University (KSU) \\ Riyadh, Kingdom of Saudi Arabia \\ E-mail: prof.sadeq@gmail.com
}

\author{
Nassr Almaflehi \\ Professor of statistics
}

Received: October 28, 2013 Accepted: November 10, 2013 Published: December 12, 2013

doi:10.5296/jsel.v1i2.4744 URL: http://dx.doi.org/10.5296/jsel.v1i2.4744

\begin{abstract}
Background: Prepositions pose major problems when translated from English into Arabic. The accurate mappings between English-Arabic prepositions are sometimes very difficult to determine by Arab learners.

Aims: This study is designed to identify the difficulties of translating the English prepositions at, in and on, which Saudi EFL students may face when translating them into Arabic. The purpose was to determine which type of the two sexes (males or females) can translate these three prepositions better.

Methods: Fifty (50) Saudi EFL students (25 males, 25 females) were asked to translate twenty (20) sentences and phrases on English prepositions at, in, and on into Arabic.

Conclusions: Findings revealed that Saudi EFL students face problems related to use and usage when transferring simple prepositions from English into Arabic. Significant differences related to the performances of both males and females where females scored higher marks than those scored by the males. These findings suggest that acquired skills and abilities involved in translation appear to be more strongly activated in the English-Arabic tasks in women as compared to men.
\end{abstract}

Keywords: Translation, Arabic, EFL students, prepositions, gender, Applied Linguistics, Approach 


\section{Introduction Chapter}

\subsection{Introduction}

Few studies have explored differences in using English prepositions out of their English contexts (Al-Adam, 2011; Charlop, et al., 2012; Ali Abu Humeid, 2013). Most studies have used samples with both genders, samples mainly consisting of men, or samples with fewer females (Guan, 2011; Kulj, et al., 2011; Chung-ling, 2012). Using of prepositions, linguistically speaking, has always been a part of human communication as it helps promote self-presentation. Although speakers of both sexes are equally prone to commit mistakes in matters concerning translating prepositions, their performance may be different based on how and why this or that preposition is used the way it is used.

Looked at it from a lexical viewpoint, translating prepositions from English into Arabic is one of the most difficult tasks for Saudi English as foreign language (EFL) students. When fully investigating this grammatical phenomenon, it is found that the main problem remains not only in recognizing the equivalent preposition, but also in understanding its use and usage in Arabic. Linguistically speaking, there are some differences in the points of views linguists look at prepositions. In the dictionary, a preposition is defined as "a word that is used before a noun, pronoun, or gerund to show that word's connection with another word, such as 'of' in 'a house made of wood', and 'by' in 'We open it by breaking the lock' ". (Longman, 1995) According to Wishon \& Burks (1980), Prepositions are "always followed by nouns or pronouns". They are, Wishon \& Burks add, "connective words that show the relationship between the nouns following them and one of the basic sentences elements: subject, verb, object, or complement." (Wishon \& Burks, 1980: p.285)

In the definition of Webster's new English dictionary (1976), a preposition is "a word or expression that combines with a noun or pronoun to form a phrase." (Webster's new English dictionary, 1976: p.395) A preposition is a part of speech that introduces a prepositional phrase. For example, in the sentence "Sadeq is reading French fiction in the room", the word in here is, grammatically speaking, a preposition, introducing the prepositional phrase "in the room". Studies show that in English, the most used prepositions are of, to, in, for, with, and on. Compared with English, the most frequent preposition in Arabic is fi (in) (Iatcu, 2011). In that sense, it can be said that prepositions function as "linkers" not only between parts of the sentence but also between all information that are mentioned in the sentence. They are not restricted to meaning expressed by nouns; rather, they extend to include those expressed by adjectives and adverbs (e.g., Wh- questions: who, why, how, when, where, etc.).Linguistically, a preposition is a grammatical phenomenon whose characteristics could involve syntactic, semantic and applied linguistic variance from different standards. Several evidences support the hypothesis of structural and functional culture reorganization in the speakers, with a different impact for male-to-female and female-to-male subjects. Linda White investigated this linguistic issue. According to her, "there are important linguistic considerations, complicated by historical and political developments." (White, 2012: p.2) Few studies have explored differences in using English prepositions. Hansard (2012), for example, divided them into two kinds based on their uses in the sentences. According to her, prepositions can 
be used for both "location and prepositions of direction. The two kinds may be either positive or negative. Prepositions of location appear with verbs, describing states or conditions, especially be; prepositions of direction appear with verbs of motion." (Hasard, 2012: p. 1)

As a matter of fact, a preposition has always been a part of human communication as it helps to promote self-presentation. Although both men and women are equally prone to commit mistakes when translating them, these mistakes may vary from one type of gender to another. It is for this reason that some researchers attempted to define the preposition to know to what extent it can help understanding human communication. In 2003, Brown concluded that a preposition is a "connector". According to him, "its function is to connect a noun or pronoun (called the object of the preposition) to another word in a sentence. It also shows how that noun or pronoun (its object) is related to the other word. Consequently, a preposition can never stand alone: it must always be within a phrase (a group of words) called a prepositional phrase. Most often, prepositions show relationships of direction, location, and time, but they can also express other relationships as well (for example, the prepositions, but, except, without, etc. show a relationship of exclusion)". (Brown, 2003: Introduction)

Prepositional effects are strong in our daily life, especially when we translate the preposition and/ or the prepositional phrase from a target language into a source language (mother tongue). Functional reorganization of neural and biological activity and facial expressions may contribute to limit our misunderstanding, and possible differences in this process may have important grammatical and syntactic implications. To that end, Bennet (1975) examined the features that are often required of prepositions. Some of these requirements are as follows:

"1- A Preposition combines syntactically with exactly one complement phrase, most often a noun phrase. In English, this is generally a noun called the object of the preposition, together with its attendant modifiers.

2- A preposition establishes the grammatical relationship that links its complement phrase to another word or phrase in the context. In English, it also establishes a semantic relationship, which may be spatial (in, on, under, etc), temporal (after, during, etc.), or logical (via ...) in nature.

3- A preposition determines certain grammatical properties of its complement (e.g. its case). In English, the objects of prepositions are always in the objective case.

4- Prepositions are non-inflecting (or "invariant"); i.e., they do not have paradigms of forms (for different tenses, cases, genders, etc.) in the same way as verbs, adjectives, and nouns in the same language. There are exceptions, though, for example in Celtic languages (see Inflected preposition)". (Bennet, 1975: p. 3-4)

Some researchers investigated differences in using electronic translation machines to translate contexts from a source language into a target language and vice versa. Most of these researchers have utilized samples with both genders, samples mainly consisting of men, or samples with six or fewer females. According to Abdulhay (2012), two electronic dictionaries could be recommended for an accurate and correct translation. Mainly, these machines are: 
Sakhr and Systran. What distinguishes these electronic translators from natural translators is, according to the researcher, their ability to avoid committing mistakes that are frequently made by human being. One of the reasons why the translation of these two translating machines is that their translation goes through some steps what the researcher called " translating process" These include: Decoding the meaning of the source text and re-encoding this meaning in the target language and the transferred meaning along with the semantics is the most significant point of focus. Some researchers looked at the issue from another angle. They believe that the reason why human being, notably EFL students makes mistakes is not because of their inability to translate the prepositions themselves, but to understand the various uses of these prepositions. Alexander (1988) for example listed some four relationships expressed by prepositions. These are:

"Space: We ran across the field,

Time: The plane landed at 425 precisely,

Cause: Travel is cheap for us because of the strength of the dollar, and

Means: You unlock the door by turning the key to the right."

(Alexander, 1988: p. 144)

Recently, there has been growing interest in understanding the prepositions to decode information from high-dimensional data. Some studies employed a support machine-based approach to identify the complex patterns of prepositional differences. Chodorow, et al., (2012) conducted many studies on such phenomenon using similar approaches. The researchers concluded to recommend the following means (methods) to be used by new researchers in the field in the future. According to Chodorow and his colleagues, understanding this linguistic phenomenon requires using more training data, combining classifiers, and using semantic information. Similar to this study, Maalej (2010) diagnosed the phenomenon and suggested some solutions. According to Maalej, the difficulties come from the different nature of Arabic and English. Secondly, teachers are not drilling prepositions properly. Moreover, an Arabic preposition is equivalent to more than one English preposition. In addition, interference from the native language is another difficulty because of its relationship with the problem of literal translation into English. Having the phenomenon diagnosed, the researchers suggested the following as crucial solutions which he called "remedial level": Prepositions should be introduced gradually based on the targeted level of learners. Furthermore, Arab EFL students need to be taught prepositions with their collocations.

Some researchers attempted to understand the phenomenon by investigating one preposition in a dialect and then comparing its use and usage to the standard language spoken in the country. Again, the aim was to fully understand the differences between the two uses. Mohammed, et al., (2012) are some of those researchers who examined such problems of translation in the one language. They discussed the use of the Arabic preposition $f i$ in the Taizzi dialect and compared it to the Arabic dialect spoken in Saudi Arabia. According to the researchers, speakers of the Taizzi dialect developed the use of $f i$ and extended its semantic 
role to cover cognitive domains that are, sociolinguistically speaking, different from its use in Arabic dialect of Saudi Arabia or other dialects of Arabic in the region. However, what proves to be true about the use of $f i$ in the Taizzi dialect needs not necessarily to be so about other dialects of Arabic. This reflects the cultural variance of prepositional usage in the Taizzi dialect in particular and other dialects of Arabic in general. The paper demonstrated that though speakers of the Taizzi dialect use $f \hat{\imath}$ in cognitive domains, they distinguish it from its use in the Arabic dialect of Saudi Arabia. Moreover, Taizzi speakers still cognitively characterize the relation holding between the trajector and the landmark as a containment relation.

Ouhalla (2011) discussed two relatively novel properties of possessive noun phrases in Arabic and explored their implications for existing analyses. While inalienable noun phrases derive from a structure where the inalienable possessum is the head noun and the possessor is its argument, alienable noun phrases derive from a structure along the lines outlined in Den Dikken (2006), where the possessum is the subject and the possessor is a predicate complement, and the relationship between the two is necessarily mediated by a relational category that corresponds to the genitive preposition in the analytic pattern. A version of this analysis is adopted in this case that accounts for additional known properties of analytic and synthetic noun phrases, including their processing figurative interface properties.

Processing figurative language, such as prepositions, is unique in that it requires one to make associations between words and message that are contextually appropriate. At the syntactic level, processing prepositional phrases has been linked to the situation wherein effective communications are being held. This functional viewpoint inspired some linguists and grammarians like As-Safi who in 2012 examined responses associated with processing prepositions compared to literal sentences. He used a new strategy which, according to him, helps him in the process of rendition of English preposition into Arabic. By employing the above strategy, As-Safi adds, "English prepositions are lexicalized instead of being replaced literally by Arabic equivalent prepositions." (As-Safi, 2012: p.3)

The strategy is hoped to reproduce a vivid, creative and dynamically communicative translation. In the following examples, some Arabic lexical items are bracketed to indicate optionality; otherwise lexicalization is obligatory. Another strategy was designed by Alayesh (2012) who investigated the effect of understanding Arabic prepositions on the use of English prepositions. He collected data from non-department students in the faculty of education who have been tested before and after explaining the different meanings of Arabic prepositions to them. The analysis of data revealed that understanding the different meanings of Arabic prepositions can eliminate the misuse of many English prepositions.

\subsection{Aims of the Study}

Prepositions are small words in both English and Arabic. Nevertheless, large numbers of Saudi EFL students, namely university students have a lot of problems concerning how and when one can translate these prepositions correctly due to that some prepositions in English have equivalents in Arabic and others do not have this feature. The current paper aims to explore the difficulties Saudi EFL students face during the process of translating the English 
prepositions at, in and on into Arabic. It also aims at identifying which gender type is better in translating these prepositions in particular. More specifically, it attempts to find answers for the following two major questions:

1. How do Saudi EFL students translate time prepositions at, in and on into Arabic? Is there any similarity/ dissimilarity between these English prepositions and their counterparts in Arabic? What are the difficulties Saudi EFL students face when they translate these English prepositions into their mother tongue?

2. How are place prepositions at, in and on translated into Arabic? Compared with the time prepositions, which kind is more difficult to be translate? Does the local dialect of the participants in question play a role?

\subsection{Limitations of the Study}

The present study is limited to the English prepositions at, in and on. The study focused on investigating the use and usage of these prepositions not as time issues, but as place subjects according to the significance they occupy in the Arabic context wherein they are translated.

\subsection{Methodology}

Fifty (50) senior students of both sexes (25 males and 25 females) study at the Department of English, college of Arts, King Saud University (KSU) were used in this study as samples. They were given a test (in terms of questionnaire) on translating English time and place preposition at, in and on administered to them by the researchers. In the test, participants were asked to translate 20 sentences and phrases (10 sentences and phrases about time prepositions and 10 sentences and phrases about place prepositions) that contain the target prepositions (at, in and on). In clearer terms, in each part, the participant was asked to translate 10 sentences and phrases where prepositions at, in and on are used. Strictly, the purpose of giving such sentences and phrases was to test Saudi EFL students' ability to translate these prepositions into Arabic. Having the participants' answers collected and prepared, they were then qualitatively and statistically analyzed. Statistical Program for Social Science (SPSS) was used to interpret the results and it was limited to describing frequencies.

\section{Analysis}

As mentioned earlier, the test posed in the questionnaire aimed to disclose the different aspects of the problem and how students commit mistakes due to the confusion of translating some English prepositions. The test contained twenty sentences and phrases, and students were supposed to translate these sentences and phrases, namely the prepositions with suitable Arabic prepositions to give the right meaning of the text. In this regard, the researchers selected the test items properly taking into consideration both time and place cases.

\subsection{Saudi EFL students and translation of English time preposition in, on and at}

In light of Saudi EFL students' responses, it is found that these students committed many errors in translating the target prepositions that have been used for time. Clearly, some of 
these Saudi EFL students were hesitated in writing their answers because of the fact that they were not sure of the appropriate Arabic preposition that should be used. In addition, there were some Arabic orthographic errors which have been made by the Saudi EFL students which makes it worse because any change in any Arabic preposition means different word; therefore, different use and usage.

The main problem for these students lies in the fact that they are not familiar with the uses and usages of the prepositions in both languages (English and Arabic). Certainly, prepositions in Arabic are syntactically different from those in English. The use and usage of a preposition may be also different in the one language taking into account the semantic and grammatical factors (time and place uses). Nor must we forget here the sociolinguistic factors whereby some prepositions are partially or completely deleted in some dialects (Al Yaari et al., 2012). Taken together, these factors confuse Saudi EFL students, notably those who lack knowledge of the same factors in the target language. Compare:

1. I'm a doctor and I work at KSU hospital.

2. He is waiting for you at the gate of the college.

3. Birds were flying above us.

4. 'Sīmāhum Fī Wujuhihim', (Their mark [i.e., sign] is on their faces [i.e., foreheads]).

5. 'Marhaba 'Ala al-'Ayn Wal-Ra's', (Great welcome to you).

6. 'Ohjumū 'Alayhim', (Attack them).

The above six sentences and phrases are selected from English (First three sentences) and Arabic (Last three sentences). In the first sentence, the preposition at is used when talking about the occupation. Notice here that the translation of this preposition in Arabic will definitely be in. In fact, this understanding of the translation of such English preposition will be the same as that of the Arabic. In clearer terms, the English speaker will understand that what is meant by the preposition at here in this sentence is the meaning of the preposition in. The difference here will be in the written word which is written in Arabic as in, while in English it is written as at. In the second example, at is used to indicate a specific place. Also, it can be used to indicate a removable place. The translation of this English preposition will be, again, the same as the former case of sentence 2 . In other words, this preposition will be orthographically translated in Arabic as in regardless the English equivalent of the Arabic preposition $f i$ (in). The third sentence cannot be understood without fully understanding of the differences in the uses and usages of the English words on, top, tip, peak, over, and above. Simply, each of the above mentioned words has its own uses and usages that can better be understood in light of a comparison between the words and other synonyms from the same language and other languages as well. What makes the problem of translating this sentence into Arabic worse is that in Arabic they only mean two things, that are the prepositions fawq (above), and 'ala (on). Regardless the differences between the English prepositions over and above, the preposition fawq here is the only counterpart of these two prepositions in this sentence. 
Likewise, in sentences 4-6, the English translation of these sentences is not sufficiently enough to cover the meanings of the three Arabic sentences. For example, in the first sentence, the Arabic preposition used is fi while the English translation is on which was supposed to be in to meet the Arabic text. However, the meaning of the Arabic translated preposition is on in both English and Arabic, but such issues needs a comprehensive understanding of the meanings of the Arabic prepositions and their English counterparts along with all related factors linked with them. The second sentence is another relative issue in Arabic where it is used to indicate a semantic and pragmatic meaning that lies behind the conventional words. 'Ala al-'Ayn Wal Ras means on the eye and the head, but what is meant by this idiomatic expression is a great welcome to valued guests. This reminds us of the phrasal verbs, prepositional phrases, allocations and collocations, and idioms in English. Using the preposition to after verbs like able (e.g., She is able to do that.) and adjectives like dangerous (e.g., It is dangerous to your health.) to mean on in both English and Arabic languages for example is a controversial issue that pose many questions among specialists from two languages like how and why the oral translation of the preposition is different from the written word, and what will happen to the meaning of the sentence if the preposition is changed into on. Omission of some prepositions from the oral translated text while the fact is that they are exist in the written sentence and/ or phrase is another problem that faces new translators who tend to translate what they see, not what they understand. This can be clearly seen in the third sentence where the Arabic preposition 'ala is mentioned in the written text, but not in the translated version of English although it is understood when translating the text. Such issues need to be understood by Saudi EFL students. The following table illustrates students' answers. Consider:

Table 1. Students' responses to time prepositions at, in, and on

\begin{tabular}{|c|c|c|c|c|c|c|c|}
\hline \multirow{2}{*}{$\begin{array}{l}\text { Ss. } \\
\text { No }\end{array}$} & \multirow{2}{*}{ The test items of time } & \multicolumn{2}{|c|}{$\begin{array}{l}\text { Correct } \\
\text { translation }\end{array}$} & \multicolumn{2}{|c|}{$\begin{array}{l}\text { Incorrect } \\
\text { translation }\end{array}$} & \multicolumn{2}{|c|}{$\begin{array}{l}\text { No } \\
\text { translation }\end{array}$} \\
\hline & & $\frac{\frac{2}{3}}{\Sigma}$ & 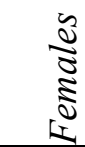 & $\frac{y^{2}}{z}$ & 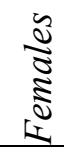 & $\frac{y^{3}}{\frac{3}{z}}$ & $\frac{\frac{\tilde{a}}{\tilde{z}}}{\tilde{\Xi}}$ \\
\hline 1 & $\begin{array}{l}\text { I am going to college at nine } \\
\text { o'clock }\end{array}$ & 8 & 11 & 16 & 11 & 3 & 1 \\
\hline 2 & The exam will start on Monday & 3 & 5 & 20 & 20 & 2 & - \\
\hline 3 & I will finish the work in ten minutes & 3 & 4 & 32 & 9 & 1 & 1 \\
\hline 4 & I learnt to drive in four weeks & 18 & 19 & 5 & 6 & 2 & - \\
\hline 5 & We will meet you at the week-end. & 4 & 6 & 15 & 14 & 8 & 3 \\
\hline 6 & The course ended on July 4, 2010. & 20 & 20 & 6 & 2 & 2 & - \\
\hline 7 & $\begin{array}{l}\text { We met } 7 \text { times in the last couple of } \\
\text { days. }\end{array}$ & 9 & 11 & 16 & 10 & 3 & 1 \\
\hline 8 & $\begin{array}{l}\text { They made an appointment with } \\
\text { him at night. }\end{array}$ & 20 & 18 & 5 & 4 & 2 & 1 \\
\hline
\end{tabular}




\begin{tabular}{|l|l|l|l|l|l|l|l|}
\hline 9 & $\begin{array}{l}\text { My father said that he won't be } \\
\text { back at noon. }\end{array}$ & 15 & 19 & 8 & 7 & 1 & - \\
\hline 10 & $\begin{array}{l}\text { My aunt will visit us in three } \\
\text { months. }\end{array}$ & 19 & 20 & 4 & 3 & 3 & 1 \\
\hline Total & 119 & 133 & 127 & 86 & 27 & 8 \\
\hline General Mean & 11.9 & 13.3 & 12.7 & 8.6 & 2.7 & 0.8 \\
\hline
\end{tabular}

As can be seen in table 1, the students' performance in translating English time prepositions was below the average. In fact their answers as senior students were unexpected. The researchers believe that it may be accounted for because of the fact that what preposition Arab student can translate well is the Arabic preposition $f i$ where they believe it to be the equivalent of any English preposition. However, this is true about certain sentences wherein this Arabic preposition becomes the appropriate preposition as in sentence 6 where 40 students translated it correctly. Again, this "correctedness" in the students' answers was not because of their lore of translating this preposition precisely; rather, it is because of the fact that it is what they (will) always translate. The same thing applies to other English prepositions where students could not translate (sentences 1, 2, 3, and 7). In comparison to other sentences, students' performance in sentences 4, 6, 8 and 10 was the best (nearly full marks). This can be clearly seen when looking at the students' incorrect answers in other sentences of the test (213). Some questions are left without answers and this is, researchers say, due to that Saudi EFL students find them difficult; therefore, they left them until they finish everything where they think they will have enough time to translate them.

Compared with the males' performance, females' performance was the best. This can be clearly observed through the general mean of the tests' correct, incorrect and left answers for both males and females $(11.9,13.3,12.7,8.6,2.7$, and 0.8 , accordingly). One of the reasonable reasons why the females' performance is better than that of the males' is that men always are, socially speaking, doing everything to afford the house financially with all what it needs. In other words, it is the man duty to tackle all affairs of the house including paying the bills, expenses of food, drinks, rent, etc.). Unlike men, women are supposed to do nothing except for that of taking care of the kids at home. This religious excellence gives the woman in the Islamic countries the time enough to study and achieve what the man cannot do. It is for this reason, however, that we find in the Islamic world in general and the Arab world in particular that women's performance in learning better than that of men. In fact, such phenomenon is not restricted on the Arab women; rather, it expands to include more than one nationality (Dyke, et al., 2009; Shao \& Skarlicki, 2009; Bonomo, 2012).

\subsection{Saudi EFL students and translation of English time preposition at, in, and on}

Generally, students' performance in place prepositions at, in, and on is not so different from that of their performance in time prepositions. It is simply because he who does not fully understand the prepositions' use and usage will normally face some difficulties in the use and usage of both time and place prepositions. However, the students' performance in the test of time prepositions will be understood when looking at their performance in the test of place prepositions as is illustrated in table 2 below. Consider: 
Table 2. Saudi EFL students' performance at place prepositions at, in, and on

\begin{tabular}{|c|c|c|c|c|c|c|c|}
\hline \multirow[t]{2}{*}{$\begin{array}{l}\text { Ss. } \\
\text { No }\end{array}$} & \multirow{2}{*}{ The test items of time } & \multicolumn{2}{|c|}{$\begin{array}{l}\text { Correct } \\
\text { translation }\end{array}$} & \multicolumn{2}{|c|}{$\begin{array}{l}\text { Incorrect } \\
\text { translation }\end{array}$} & \multicolumn{2}{|c|}{$\begin{array}{l}\text { No } \\
\text { translation }\end{array}$} \\
\hline & & $\frac{\sqrt[s]{a}}{\frac{s}{z}}$ & 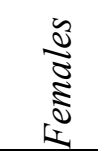 & $\frac{\sqrt[b]{a}}{\tilde{s}}$ & 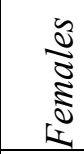 & $\frac{\sqrt[y]{3}}{\Sigma}$ & 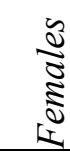 \\
\hline 1 & I arrived $\underline{a t}$ the hotel. & 17 & 21 & 4 & 3 & 3 & 2 \\
\hline 2 & He is standing at the door. & 13 & 29 & 5 & 2 & 1 & - \\
\hline 3 & We were at home all weekend & 12 & 30 & 5 & 1 & 1 & 1 \\
\hline 4 & $\begin{array}{l}\text { Three players are on the } \\
\text { soccer field. }\end{array}$ & 14 & 19 & 10 & 4 & 2 & 1 \\
\hline 5 & $\begin{array}{l}\text { There is a new roof on the } \\
\text { house }\end{array}$ & 19 & 21 & 4 & 3 & 3 & - \\
\hline 6 & $\begin{array}{l}\text { Write it down on a piece of } \\
\text { paper. }\end{array}$ & 15 & 32 & 2 & 1 & - & - \\
\hline 7 & The boxers are in the ring. & 22 & 23 & 3 & 1 & 1 & - \\
\hline 8 & $\begin{array}{l}\text { I read about it in the } \\
\text { newspapers. }\end{array}$ & 19 & 19 & 4 & 4 & 3 & 1 \\
\hline 9 & $\begin{array}{l}\text { He's a doctor. He works at the } \\
\text { national hospital. }\end{array}$ & 15 & 17 & 5 & 6 & 4 & 3 \\
\hline 10 & I live in Dhamar. & 23 & 27 & - & - & - & - \\
\hline \multicolumn{2}{|c|}{ Total } & 169 & 238 & 42 & 25 & 18 & 8 \\
\hline \multicolumn{2}{|c|}{ General Mean } & 16.9 & 23.8 & 4.2 & 2.5 & 1.8 & 0.8 \\
\hline
\end{tabular}

In comparison to students' performance in table 1 wherein the majority of them scored low marks as they could not translate most of the sentences correctly, in table 2, the majority of them translated the sentences correctly. This can be clearly seen in the number of incorrect sentences where we find that students' mistakes in time prepositions are more than those of place prepositions. Taking into a consideration the distinctive features of the Arabic preposition that Saudi EFL students ignore, it is not surprised that they could not translate sentence 4 properly.

Statistically speaking, the students' performance at translating English place preposition into Arabic (both males and females) overpasses their performance in translating English time prepositions into Arabic (General Means=16.9, 23.8 vs 11.9 and 13.3, respectively). In fact, even when looking at the performance of those who could not translate very well, one can easily identify that their performance in time preposition is worse than that of place prepositions (General Means=12.7, 8.6 vs 4.2, and 2.5, accordingly). Zero scores refer to the fact that students could not find an Arabic translation due to the lack of knowledge in Arabic prepositions and their multiple uses and usages. Significant high versus low scores among participants $\times$ condition effects were observed in students' responses of both sexes, despite 
similar performance on some of the sentences being translated in both time and place tasks. In most clusters with significant interactions, the low scores demonstrated relatively less, whereas the high scores demonstrated more.

\section{Conclusions}

There is not a consensus in global and domain-specific self-esteem or even in the incidence of some definitions related to prepositions. Linguists worldwide agree upon the fact that there are slight differences in the performances underlying one's own self-esteem. In this paper, the researchers investigated these differences in the performances of the Saudi EFL students while subjects (50 students of both sexes) performed an implicit self-esteem task, using a questionnaire. While student's high performance was significantly observed in translating English place prepositions, this ability was not activated in the English time prepositions in the incongruent condition ( self = negative) compared with the congruent condition (self = positive) Additionally, scores on the explicit self-esteem test were negatively correlated with time prepositions and positively correlated with place prepositions. Furthermore, the functional relationships among the students' responses found by direct translation to the given text were discussed based on the Arabic model of translating the sentences of the test. These showed that, compared to time prepositions, English place prepositions more firmly store even the incongruent associations as part of their schematic self-knowledge, and such associations automatically activate the Arabic lore for linguistic responses and control, in which knowledge of both languages (source and target languages i.e., Arabic and English) plays a central role.

Findings also showed significant differences in the abilities of the students in translating English prepositional sentences into Arabic during any experimental phases. However, during test conditioning, there were significantly greater changes in the performance of the students, namely in place prepositions compared with time prepositions.

These results indicate performance differences among participants despite similar peripheral autonomic responses. Such differences can be clearly seen in light of tables 1 and 2 . As is seen in the two tables, the percentages vary from one question to another. Compared with correct translated sentences, incorrect translated answers registered high percentages in time prepositions, notably with males (Table 1). For better illustration, one can compare the outcomes of the two tests (time and place) in light of the following four comparative figures. Compare:

Figures 1 and 2

Saudi EFL students' performance in translating time prepositions at, in and on: Comparisons between correct, incorrect and zero translation of both males and females. 


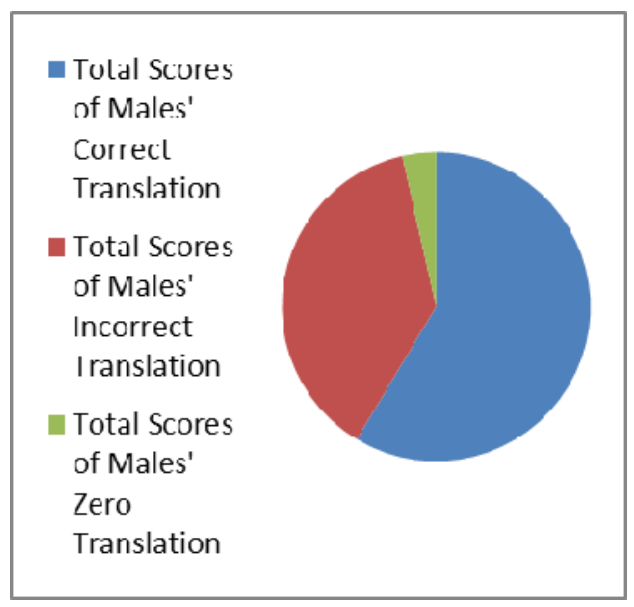

Figure 1

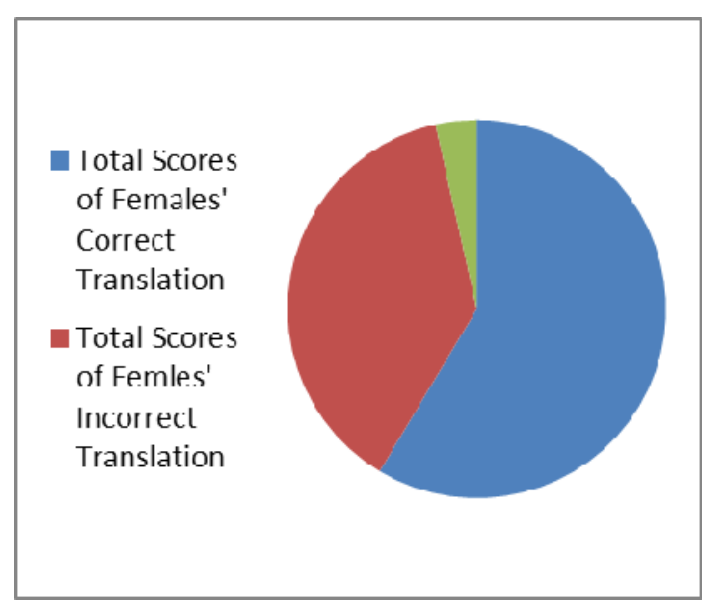

Figure 2

Figures 3 and 4

Saudi EFL students' performance in translating place prepositions at, in and on: Comparisons between correct, incorrect and zero translation of both males and females.

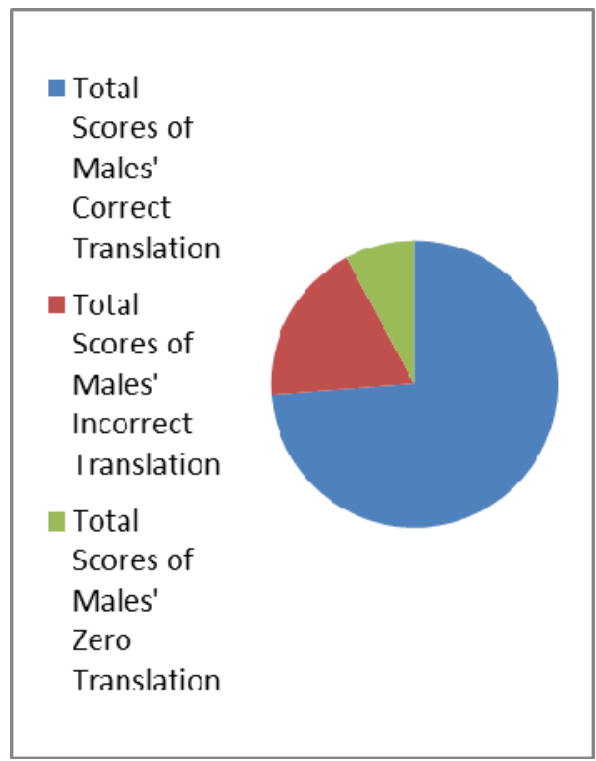

Figure 3

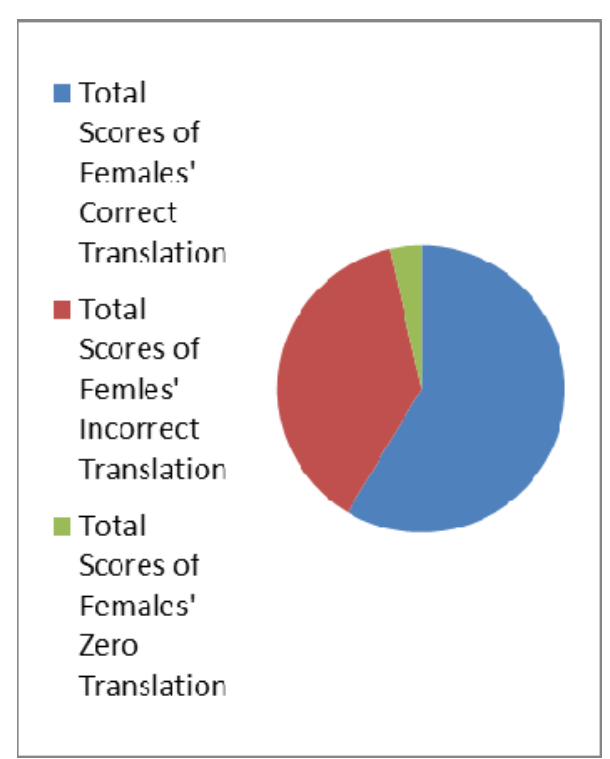

Figure 4

Based on the outputs of the four figures, it can be said that Saudi EFL female students are better than male students in translating the prepositions in, on and at. Generally, Saudi EFL students sometimes tend to use their own language to express or compensate the preposition they want to translate from their language or to other language (s). This is why some times they leave the text without any translation (zero translation). They tend (unconsciously) to leave it until the 
end of the time, thinking that somehow they will know the best translation since they do not have the right words to be used here. Such phenomenon is due to lack of prepositions' patterns and structures and the result is what can be seen when these Saudi EFL students express themselves orally or in writing. Researchers believe that one of the causes is the influence of mother tongue (L1). Saudi EFL students cannot separate the two grammatical systems of both Arabic and English. They mixed them together the moment they start to translate. Needless to repeat here the lack of knowledge of both use and usage of every single preposition in both source and target languages (Arabic and English) affects the overall performance of the participants.

Saudi EFL students of both sexes cannot distinguish the English preposition on for example from its equivalents in the same language into, inside, and at. Actually, they cannot even differentiate between sentences like "look at my eyes.", and "look in my eyes." They cannot tell how and why the preposition at is used in the former while the preposition in is used in the latter or what if we reverse the two prepositions in the sentences. The same thing applies to sentences like "He came in time.", "He came at time.", and "He came on time." Such controversial issues need to be fully explained and discussed in details by the Arab grammarians, instructors, school teachers, university professors and other experts in particular sectors in the field. Clearly, the misunderstanding of some of these words used in the test caused Saudi EFL students to commit errors. In spite of the fact that both Arabic and English prepositions have some distinctive features in common, they differ in both number and usage. Nor must we forget to mention here that whereas Arabic has over 40 prepositions, English has less than 30 (al-Anbārī, 1995; Bennett, 2008) and this is another problem.

Semantic effects on the prepositions play another pivotal role on both Arabic and English prepositions. He who understands the semantic characteristics and the colloquial varieties can understand the differences between Arabic and English prepositions. It is integrated with many factors including the abstract, phonological, morphological and metaphorical usages. While some accents allow some degrees of errors, others do not. Such misunderstanding or misusing of all these factors cause what is known as the "systematicity of errors" be it in the use or usage of prepositions.

\section{Recommendations}

Arab universities are recommended to establish new programs that help Saudi EFL students become creative and professional translators. One of these programs should enhance Saudi EFL students and strengthen their ability in translation. They are recommended to send their students, notably senior students study at the colleges of translation abroad to improve the language he / she studies at home university. It is in this way only that one can create professional translators who have already practiced the language they study with its native speakers. Departments of foreign languages are also recommended to provide their students with all materials that guarantee the best knowledge for these students. They have also to encourage in their students the sense of research where they can "google" for any information they need about foreign languages. 
Universities' libraries should provide all foreign languages' literature to their readers and visitors. Programs including seminars, visiting a western institution (e.g., cultural councils, embassies, etc.) are also recommended to link Saudi EFL students with the western culture. Universities should send their students to study in foreign centers that belong to the western embassies regularly. There must be a continuous follow-up and a comprehensive evaluation for the students' performance in these centers.

Saudi EFL students, namely senior students are also advised to try all means that may help improve their translation like translating long sentences, and/ or paragraphs about themselves. Alternatively, they can translate stories from and to their language. Passages are good environment for translation because they include hundreds of prepositions. Saudi EFL students should translate any passage they read and in case they find some difficulties, they can ask their professors to help them and revise what they have translated. They can also visit Arabic language departments to meet the professors there and benefit from them, especially when the problem is relating to Arabic syntax. Saudi EFL students can also watch western channels including News channels like $\mathrm{CNN}, \mathrm{BBC}$, etc. and then translate orthographically what they have already watched. They are also recommended to listen to the radio cassettes and then translate what they have ust listened to.

Saudi EFL students can also translate the words with diacritics and then practice the use of prepositions to improve their translation skill. Furthermore, they can listen to music, notably songs which are full of prepositions since they have the same effect on non-native speakers as direct translation does (Kenneth \& Wilcox, 1995). EFL students at Saudi Arabia universities are also advised to read both Arabic and English literature including poems, novels, fictions, plays, and dramas. More importantly, they have to recite Holy Quran and read also the prophetic narrations as they are written in the highest standards of grammar. They have to try their best to parse the sentence they read as this will definitely help them identify how and why this preposition is translated in this/ that way. They can also make use of cards where they can see the picture and translate what they have seen in it and check the meaning later in their dictionaries. Finally, the researchers recommend for further studies in this field using different methodology and more participants.

\section{References}

Abdulhay, N. (2012). Problems of translation from Arabic into English. Cairo: Cairo Bookstore.

Al-Adam, H. (2011). Comprehension and Production of Prepositions by Palestinian-Speaking Broca's Aphasics . Journal Of The All India Institute Of Speech \& Hearing, 30125-129.

al-Anbārī, A. (1995). Asrār al-'Arabiyah. T11. Tahqū̄q al-Duktūr Fakhr Șālih Qudārah . Bayrūt : Dār al-jil.

Alayesh, M. A. (2012). The Effect of Arabic Prepositions On the use of English Prepositions. Mansoura: Mansoura University.

Alexander, L. G. (1988). Longman English Grammar. Oxford: Oxford University Press. 
Ali-Abu-Humeid, A. (2013). Compound Prepositions Used by Iraqi EFL University Students. International Journal Of English Linguistics, 3(2), 98-114. http://dx.doi.org/10.5539/ijel.v3n2p98.

Al-Yaari, S. (2009, Oct.). Prepositions. King Saud Journal, pp. 8-17.

Al-Yaari, S., Al-Hammadi, F., \& Luwa, A. (2012). Vowel Deletion in Arabic Dialects of Yemen (ADY): A Linguistic Perspective. International Journal of Linguistics, 4(2), 430-458. http://dx .doi.org/ 105296/ijl.v4i2.1657.

As-Safi, A. B. (2012). Translation Theories, Strategies and Baisc Theoretical Issues. Putra: Putra Univeristy Press.

Bennett, C. D. (1975). Spatial and Temporal Uses of English Prepositions: An Essay in Stratificational Semantics. London: Longman.

Bennett, D. C. (2008). English Prepositions: A Stratificational Approach. Journal of Linguistics / Volume 4 / Issue 02, pp 153-172. http://dx.doi.org/10.1017/S0022226700001869.

Bonomo, V. (2012). The effects of gender specific instructional strategies: Examining the reading achievement of boys in single-sex schools. Indiana University of Pennsylvania). ProQuest Dissertations and Theses, 129. Retrieved from http://search.proquest.com/docview/955180665? accountid=44936. (955180665)., 2-3.

Brown, B. (2003, Sep.). Prepositions. Academic Center and the University of Houston-Victoria, p. 570.

Charlop, H. M., Miltenberger, A. C., \& Bandar Miranda, B. (2012). Teaching children with intellectual challenges to learn prepositions: Using a treatment package of computer-based photographs, time delay prompting, video self-modeling, and positive reinforcement. Evidence-Based Communication Assessment \& Intervention, 6(3), 113-119. http://dx.doi.org/10.1080/17489539.2012.740816.

Chodorow, M., Tetreault, J. R., \& Han, N.-R. (2012, Dec.). Detection of Grammatical Errors Involving Prepositions. TESOL Journal, pp. 1-4.

Chung-ling, S. (2012). A Corpus-Aided Study of Shifts in English-to-Chinese Translation of Prepositions. International Journal Of English Linguistics, 2(6), 50-62. http://dx.doi.org/10.55 39/ijel.v2 n6p50.

de-Dikken, M. (2006). Relators and Linkers: The Syntax of Predication, Predicate Inversion, and Copulas. Linguistic Inquiry Monograph Forty-Seven, pp.2-3.

Douglass, W. (1979). Translating the Culture. Beltran: Basque Sheepman of the American West (University of Nevada Press, Reno and Las Vegas. p. xiii.

Dyke, A. S., Zuverza, V., Hill, L. A., Miller, J. B., Rapport, L. J., \& Whitman, R. (2009). Gender Differences in Lateralized Semantic Priming. Developmental Neuropsychology, 34(4), 381-392. http://dx.doi.org/10.1080/87565640902964516. 
Guan, X. (2011). The Formalization of English Structures with Preposition "in" and Their Chinese Translations. Studies In Literature \& Language, 3(3), 25-28. http://dx.doi.org/10.3968/j.sll.1923156320110303.033.

Hansard, M. (2012, Jan). Prepositions of Location: At, In, On. Purdue University Online Writing Lab, pp. 1-8.

Iaţcu, T. (2011). On English Prepositions . Studia Universitatis Petru Maior - Philologia, 10166-175.

Krulj, B. S., \& Trbojevic, S. (2011). Influence of Realization of Prepositions and Prepositional Phrases on Their Proper Use in Professional Medical Texts in English. Acta Facultatis Medicae Naissensis, 28(4), 235-240.

Maalej, Z. (Jul.). Spatial scenes in Arabic and English. KSU Journal, pp. 3-9.

Mohammed, T. M., Ho-Abdullah, I., \& Hua, T. K. (2012, May). The Semantics Of (fii) In Taizzi Dialect: A Cultural Variation Perspective. GEMA Online ${ }^{\mathrm{TM}}$ Journal of Language Studies, p. 12.

Ouhalla, J. (2011, March). Preposition-possessum . Brill's Annual of Afroasiatic Languages and Linguistics, pp. 111-139.

Shao, R., \& Skarlicki, P. D. (2009). The Role of Mindfulness in Predicting Individual Performance. Canadian Journal Of Behavioural Science, 41(4), 195-201. http://dx.doi.org/10.1037/a0015166.

West, K. D., \& Wilcox, D. W. (1995). "A Comparison of Alternative Instruments Variables Estimators of a Dynamic Linear Model," NBER Technical Working Papers 0176. National Bureau of Economic Research, Inc, 1-3.

White, L., \& McClanahan, T. (1998). Translating the Culture . University of Neveda-Reno and Idaho Humanities Council , 4-5.

Wishon, G., \& Burks, J. (1980). Let's Write English. New York : American Book Company .

\section{Appendix}

\section{The questionnaire (The test)}

Translate the following sentences into Arabic

1) I am going to college at nine o'clock.

2) I arrived at the hotel.

3) He is standing up at the door. 
4) We were at home all weekend.

5) Three players are on the soccer field.

6) There is a new proof on the house.

7) write it down on a piece of paper.

8) The exam will start on Monday.

9) The boxers are in the ring.

10) I read about it in the newspapers.

11) I will finish the work in ten minutes.

12) I learnt to drive in four weeks.

13) We will meet you at the week-end.

14) The course ended on July 4, 2010.

15) We met 7 times in the last couple of days.

16) They made an appointment with him at night.

17) My father said that he won't be back at noon. 
18) My aunt will visit us in three months.

19) He's a doctor. He works at the national hospital.

20) I live in Dhamar.

\section{Copyright Disclaimer}

Copyright reserved by the author(s).

This article is an open-access article distributed under the terms and conditions of the Creative Commons Attribution license (http://creativecommons.org/licenses/by/3.0/). 